\title{
THE USE OF THE BLADDER WASH-OUT TEST IN PATIENTS WITH SPINAL CORD LESIONS WHO HAVE URINARY TRACT INFECTION*
}

\author{
By J. J. Wyndaele, M.D., W. Oosterlinck, M.D., W. A. De Sy, M.D. \\ and H. Claessens, M.D. \\ Department of Urology and Rehabilitation Centre, University of Ghent, Belgium
}

Summary. In 42 patients with a spinal cord lesion and chronic urinary tract infection the bladder wash-out test was performed to locate the site of infection.

The test was easy to perform and no complications occurred. The test could not be performed in only one patient.

Differentiation between upper and lower urinary tract infection was possible in 36 patients (43 tests). By using the test, precise treatment was possible for 23 patients, of whom 17 were cured.

Key words: Spinal cord lesions; Bladder wash-out test; Urinary tract infection.

\section{Introduction}

To kNOw the exact site of infection may be a very important factor in the correct management of patients with urinary tract infection.

Chronic or recurrent urinary tract infections are frequent in patients with spinal cord lesions. Localisation of the infection in these patients may be the clue to a definite diagnosis, and proper treatment.

Among other, procedures, the bladder wash-out test has been proposed as a technique which makes differentiation between upper and lower urinary tract infection possible.

The purpose of this study is to evaluate its usefulness in patients with spinal cord lesions and chronic or recurrent urinary tract infection.

\section{Methods}

We perform the bladder wash-out test approximately as described by Fairley and associates (Fairley et al., I967).

A Foley catheter is introduced into the bladder, and the first urine specimen is collected for bacterial culture. The bladder is emptied, then $50 \mathrm{ml}$ of a 0.2 per cent Neomycin solution are instilled into the bladder for 30 minutes. After emptying the bladder, it is washed ten times with I00-300 $\mathrm{ml}$ sterile water (depending on the bladder capacity). A specimen of the last wash-out is kept for culture. Then three urine samples are collected with ro minutes intervals. An intravenous injection of frusemide $40 \mathrm{mg}$ is not used routinely anymore as this may reduce the bacterial count in the final three specimens, which makes it more difficult to distinguish between an upper tract infection and a lower tract infection (Fairley et al., I97I). The site of infection is determined on the basis of the bacterial counts

$\star$ Read at the Annual Scientific Meeting of the International Medical Society of Paraplegia, Athens, Greece. October 1982. 
in these several urine specimens. Typical results of bacterial counts (organisms per $\mathrm{ml}$ ) are given in Table I.

\section{TABLE I}

Typical results of bacterial counts (organisms per $\mathrm{ml}$ ) in urine specimens collected in bladder wash-out test in upper and lower urinary tract infection

\begin{tabular}{lcccccc}
\hline Site of Infection & $\begin{array}{c}\text { Bladder } \\
\text { Specimen }\end{array}$ & $\begin{array}{c}\text { After } \\
\text { Neomycin }\end{array}$ & $\begin{array}{c}\text { Last } \\
\text { Wash-out }\end{array}$ & I0 min & $20 \mathrm{~min}$ & $30 \mathrm{~min}$ \\
\hline Upper tract & $>100.000$ & 0 & 1000 & 50.000 & 70.000 & 100.000 \\
Lower tract & $>100.000$ & 0 & 0 & 0 & 0 & 0 \\
\hline
\end{tabular}

Upper urinary tract infection is assumed if a urine specimen collected within 30 minutes after the last bladder wash-out contained more than 3000 bacteria per $\mathrm{ml}$ or if this specimen contained more than five times as many bacteria as were present in the last bladder wash-out specimen.

Lower urinary tract infection is assumed to be present if cultures of urine specimens collected after the bladder wash-out remained sterile (Fairley et al., I97 I).

In some patients serum antibody titres were determined by indirect bacterial haemagglutination (Hewstone and Whitacker, I969).

In a few male patients a three glass urine specimen test was performed to differentiate between prostatitis and other lower urinary tract infection.

\section{Material}

Since I979, 54 bladder wash-out tests were performed in 42 patients with spinal cord lesions: nine females and 33 males, ranging in age from 8-77 years (mean age 36 years). Thirty patients had a spinal cord injury, six a brainstem lesion and six myelodysplasia.

All of these patients had chronic or recurrent urinary tract infection and failure of several periods of antibiotic treatment. None had vesicoureteral reflux or a large vesical diverticulum, conditions that can falsify the results of the bladder wash-out test (Oosterlinck et al., I98I).

The results in five patients on intermittent selfcatheterisation, five patients with renal calculi, four patients with radiological signs of pyelonephritis and two patients with bladder stones were evaluated separately. The correlation between these special conditions and the site of infection was determined.

The test was repeated twice in eight patients and three times in two patients. The new tests were done after removal or evacuation of a kidney stone (four patients) or because of remaining problems of urinary tract infection (six patients).

Thirty-three bladder wash-out tests were performed on hospitalised patients and 2 I tests on ambulatory patients.

\section{Results}

Upper urinary tract infection was found in ten patients (I I tests). The infecting organisms are listed in Table II. On intravenous pyelography 
TABLE II

Infecting organisms in upper and lower urinary tract infection

\begin{tabular}{lcc}
\hline Infecting Organism & Upper Tract Infection & Lower Tract Infection \\
\hline E-Coli & I & 4 \\
Klebsiella Spp. & 3 & 7 \\
Proteus Spp. & I & 5 \\
Providencia Stuart & I & 2 \\
Pseudomonas Spp. & 2 & IO \\
Enterococcus & 2 & I \\
Staph. Albus & - & I \\
Different organisms & I & 2 \\
\hline
\end{tabular}

(I.V.P.) three patients had kidney stones and two patients had pyelonephrotic scarring of both kidneys. The I.V.P. was normal in four other patients.

Lower urinary tract infection was found in 26 patients (32 tests). The infecting organisms are listed in Table II. One patient had previously been operated on for vesico-renal reflux. Her I.V.P. showed signs of pyelonephritis. Two patients had a kidney stone and two a bladder stone.

Doubtful results were found in five tests (Table III). The bladder wash-out test could be repeated only in patient number three. His second test was compatible with an upper urinary tract infection. He had a calculus in the right kidney.

\section{All cultures sterile}

In five bladder wash-out tests all urine specimens afterwards proved to be sterile. Three patients had started another antibiotic treatment just before the test was done. Two patients had positive urine cultures before and after the bladder wash-out test. There may have been a mistake in the laboratory.

\section{Failure}

One patient with a brainstem lesion evacuated the neomycine solution immediately after its instillation to the bladder. Even after a parasympathicolytic drug was administered the same result ensued.

\section{Serum antibody titres}

In I4 patients serum antibody titre against the infecting organism was determined. The blood sample was taken during the bladder wash-out test.

All titres were $\leqslant \mathrm{I} / 40$. In I I patients the bladder wash-out test demonstrated a lower urinary tract infection. sterile.

In two patients the results were doubtful and in one all cultures were

The three-glass urine specimen test was performed in nine patients suspected to have prostatitis. Results of the test were doubtful in four patients: all urine specimens showed the same degree of pyuria and all cultures had 
TABLE III

Doubtful results in bladder wash-out tests

\begin{tabular}{|c|c|c|c|c|c|c|c|}
\hline \multirow[b]{2}{*}{ Patient } & \multirow[b]{2}{*}{ Bacteria } & \multicolumn{6}{|c|}{ Organisms per ml } \\
\hline & & $\begin{array}{l}\text { Bladder } \\
\text { Specimen }\end{array}$ & $\begin{array}{c}\text { After } \\
\text { Neomycin }\end{array}$ & $\begin{array}{c}\text { Last } \\
\text { Wash-out }\end{array}$ & IO $\min$ & $20 \mathrm{~min}$ & $30 \mathrm{~min}$ \\
\hline I & E-Coli & $900 \cdot 000$ & 0 & $<500$ & 2500 & 1000 & $<500$ \\
\hline 2 & Kleb. pneum. & $>10^{6}$ & 500 & 500 & 2000 & I000 & 500 \\
\hline 3 & Pseud. Aerug. & $>10^{6}$ & 10.000 & 0 & 1000 & 0 & 1000 \\
\hline 4 & Klb. pneum. & 500 & 0 & 0 & $<500$ & 0 & $<500$ \\
\hline 5 & Prot. Vulg. & $>10^{6}$ & $10 \cdot 000$ & $50 \cdot 000$ & $50 \cdot 000$ & $50 \cdot 000$ & $50 \cdot 000$ \\
\hline
\end{tabular}


the same bacterial count. Prostatitis was found in four patients, and in all of them the bladder wash-out test demonstrated a lower urinary tract infection. No prostatitis was found in one patient. His bladder wash-out test also demonstrated a lower urinary tract infection. The correlation in special groups of patients is shown in Table IV.

TABLE IV

Correlation bladder wash-out test in special groups

\begin{tabular}{lcccc}
\hline & & \multicolumn{3}{c}{ Results B.W.O.-test } \\
\cline { 3 - 5 } & Patients & Upper Tract & Lower Tract & Other \\
\hline Intermittent selfcath. & 5 & - & 4 & I \\
Renal calculi & 5 & 3 & 2 & - \\
X-rays pyelonephr. & 4 & 2 & I & I \\
Bladder stone & 2 & - & 2 & - \\
\hline
\end{tabular}

TABLE V

Results of treatment guided by the bladder wash-out test

\begin{tabular}{lcccc}
\hline Site of Infection & No Patients & Cure & Failure & Unknown \\
\hline Upper urinary tract & IO & 4 & 4 & 2 \\
Lower urinary tract & 22 & I3 & 2 & 7 \\
\hline
\end{tabular}

\section{Results of treatment (Table V)}

Follow-up was complete in 23 hospitalised patients but incomplete in nine ambulatory patients.

Ten patients with an upper urinary tract infection were treated with appropriate antibiotics for several weeks or months after removal of kidney stones. Four had sterile urine and four remained infected. In two patients follow-up was incomplete.

Of 22 patients with a lower urinary tract infection the urine became sterile in 13 and remained infected in two. In seven patients follow-up was incomplete.

Four patients on intermittent selfcatheterisation received a low dose antiseptic or antibiotic treatment. This treatment was successful in only one patient. Her urine has remained sterile since then. The other three patients continue to have an urinary tract infection.

\section{Discussion}

If a urinary tract infection is difficult to treat, knowledge of the exact site of the infection is a major step in its correct management.

In a number of patients with a spinal cord lesion, urinary tract infection proves difficult to cure. The urinary tract of these patients can be severely damaged and apart from micturition disorders several urological complications may be present (renal calculi, pyelonephritis, bladder stones, 
prostatitis, etc.). Treatment of these complications however is not always sufficient to cure these patients.

In others, no urological complication may be found and yet chronic infection continues despite proper antimicrobial treatment. In these patients knowledge of the exact site of the urinary tract infection can be the clue to successful treatment.

It is not possible to rely on symptoms for localisation (Fairley et al., I97 I). Moreover, most patients with a spinal cord lesion and urinary tract infection are symptom-free.

$\mathrm{X}$-rays are valuable to diagnose urological complications but they cannot with certainty differentiate between an upper and lower urinary tract infection. In this study the results of the bladder wash-out test correlate with the pathological findings on intravenous pyelography.

A normal I.V.P. does not exclude the presence of an asymptomatic renal infection. In this group four patients had a normal I.V.P. and an upper urinary tract infection.

The bladder wash-out test proved to be a reliable technique that allows differentation between upper and lower urinary tract infection in most patients with a spinal cord lesion.

The test is easy to perform. It is rather time-consuming ( $\mathrm{I} \frac{1}{2}$ hours). In our department it is performed by a specially trained nurse.

No complications occurred, except in one patient. The instillation of neomycin and the different wash-outs could be done without difficulty. In patients with very cloudy urine we usually washed out the bladder with sterile water before the neomycin solution is instilled. In our experience this was necessary to guarantee sufficient action of the neomycin in the bladder. If not done, only 30 per cent of patients with cloudy urine had a sterile urine culture after the neomycin instillation.

The use of serum antibody titres determination for the localisation of a urinary tract infection is not generally accepted. Published results are contradictory. (Fairly et al., I97I; Hewstone and Whitacker, I969; Jodal, I975). In this study we had serum antibody titres determined but only in patients with a lower urinary tract infection. All titres were very low $(\leqslant \mathrm{I} / 40$ ). This correlates well with the findings of others (Hewstone \& Whitacker, 1969) but the absence of results in patients with upper urinary tract infections makes any conclusion impossible.

The antibody coated bacteria test is not yet performed in our hospital. This test seems accurate in the differentiation of upper and lower urinary tract infection (Kwasnik et al., I979; Jansen and Roberts, 1977). We hope to be able to perform this test in the future.

The bladder wash-out test tells nothing about the side of an upper tract infection. If indicated ureteral catheterisation or even better, kidney puncture should be performed.

The diagnosis of prostatitis in patients with a spinal cord lesion is not easy. When suspected in patients with chronic lower urinary tract infection a three glass-urine specimen test should be done although doubtful results are not uncommon in patients with a neuropathic bladder. (Four of nine tests in this study).

The results of treatment obtained by using the bladder wash-out test were satisfactory. In those who could receive precise treatment and were 
controlled afterwards, 50 per cent of the patients with an upper tract infection and 74 per cent of the patients with a lower tract infection were cured.

\section{RÉSUMÉ}

Pour déterminer la localisation exacte d'une infection chronique urinaire chez 42 patiënts à lésion médullaire, la méthode du 'bladder wash-out' fut utilisée. A une exception près ce test pût être fait facilement et sans complications.

La distinction entre une infection rénale et une infection vésicale fut possible chez 36 patients (43 tests.) 23 patients ont pu avoir un traitement dont le choix fut basé sur les résultats du test. 17 sont guéris.

\section{ZUSAMMENFASSUNG}

Bei 42 Patienten mit Rückenmarkverletzungen und chronischer Harnweginfektion wurde der Blase-Auswaschtest angewandt mit dem Zweck diese Infektion zu lokalisieren.

Im allgemeinen war der Test leicht ausführbar und ergaten sich Keine Komplikationen. Bei slosz einem Patienten Konnte er nicht ausgeführt werden.

Differenzierung zwischen Infektion des oberen bzw. des unteren Harnwegs ermöglichte sich bei 36 Patienten (43 Teste). Die Behandlung von 23 dieser Patienten wurde auf diesen Test gegründet; 17 unter ihnen Konnten geheilt werden.

\section{REFERENCES}

Fairley, K. F., Bond, A. G., Brown, R. B. \& Habersberger, P. (1967). Simple test to determine the site of urinary tract infection. Lancet, 2, 427-428.

FaIRLEY, K. F., CARSON, N. E., GUTCH, R. S. et al. (I97I). Site of infection in acute urinary tract infection in general practice. Lancet, 2, 615-618.

Hewstone, A. S. \& WhitackeR, P. J. (I969). The correlation of ureteric urine bacteriology and homologous antibody titer in children with urinary infection. Fournal of Pediatrics, 74, 540-543.

JANSEN, K. L. \& RoBerTs, J. A. (1977). Non-invasive localization of urinary tract infection. Fournal of Urology, $117,624-627$.

JoDAL, U. (1975). The immune response to urinary tract infections in childhood. I. Serological diagnosis of primary symptomatic infection in girls by indirect hemagglutination. Acta paediatrica Scandinavia, 64, 96-104.

KwASNik, I., KLAUBER, G. \& TILTON, R. C. (1979). Clinical and laboratory evaluation of antibody coated bacteria test in children. Fournal of Urology, 121, 658-661.

Oosterlinck, W., Nemeth, J. \& Verbaeys, A. (I98I). The bladder wash-out test in urological practice. Fournal of Urology, 126, 75-76. 